\title{
Predictors of Surgical Outcome of Abdominal Trauma in Tertiary Care Centres of Nepal
}

\section{Bikash Bikram Thapa', Rajan Gurung ${ }^{2}$, Robin Basnet ${ }^{3}$ and Narayan Thapa ${ }^{1}$}

${ }^{1}$ Department of Surgery, Nepalese Army Institute of Health Sciences, Kathmandu, Nepal; ${ }^{2}$ Department of Surgery. Patan Academy of Health Sciences, Lalitpur, Nepal; ${ }^{3}$ Department of Surgery, National Academy of Medical Sciences, Kathmandu, Nepal.

\section{ABSTRACT}

Introduction: The abdominal trauma is a surgical emergency most of which are preventable and many of them could have good outcome with timely management by dedicated trauma system. It is not only the rising health problem but also the social and economic burden. A study on abdominal trauma can guide to cost-effective quality management of the patients. This study is undertaken to study and evaluate the predictors of surgical outcome in abdominal trauma patients in tertiary care centers in Nepal.

Methods: Seventy five patients with abdominal trauma who underwent surgical intervention were evaluated prospectively inside the inclusion criteria. Ethical approval was obtained. The data on demographic pattern, clinic-radiological findings, abdominal trauma index, injury severity scale, operative findings, infectious complications, and mortality were collected. Chi square test was used for statistical analysis.

Results: Out of 75 patients male to female ratio was $4.6: 1$. Blunt trauma (49) was the common cause of abdominal injury. Accidental abdominal injury happened in $73 \%$ (55) and fall from height was common mode of abdominal organ injury $40 \%$ (30). The overall morbidity and mortality were $30.6 \%$ and $9.3 \%$ respectively. Age $>30$ years, Shock at presentation, Operative Delay $>24$ hours, and trauma score (ATI $>15$ and ISS $>15$ ) were all good predictors of surgical outcome of patients with abdominal trauma $(\mathrm{p}<0.05)$.

Conclusion: The predictors of surgical outcome were patient's age, clinical status at presentation and delay in surgical intervention. Trauma score (both ATI and ISS) are equally important in predicting outcome which are necessary for monitoring patients care and the quality of trauma systems.

Keywords: abdominal trauma, trauma surgery, trauma outcome, trauma score

\section{INTRODUCTION}

Globally, injury is the seventh leading cause of death and in Nepal, trauma or injury contributed to $9 \%$ of total mortality and is the third leading cause of death ${ }^{1}$.The economically active population between 20-50 years of age was mostly involved in injuries. ${ }^{2}$ Trauma deaths occur at traditionally recognized time points after injury and have trimodal

Correspondence: Bikash Bikram Thapa, Department of Surgery, Shree Birendra Hospital, Chhauni, Kathmandu, Nepal. Email:bbthapa@gmail.com 
distribution. The third peak in mortality represents deaths that occur 24 hours after injury and includes late mortality from infection and multiple organ failure.

Complications after abdominal surgery can be divided into major and minor categories depending on the assessed severity and physiological upset. ${ }^{3}$ Alamshah et $\mathrm{al}^{4}$ in 2010 has classified risk factors for outcome into 3 classes as main (real), moderate and predictive. Referral delay, delay in diagnosis and treatment, shock on arrival, multiple intraabdominal visceral injuries, and severe acidosis were identified as the main risk factors. Age, multiple surgery, ICU admittance, electrolyte imbalance, and mismanagement during transfer were identified as moderate risk factors. Low hemoglobin, hypoxemia, observation in multiple services, and distance $>100$ kilometers were identified as predictive factors. The severity of traumas in hospitalized patients was characterized by means of different trauma score system. ${ }^{5}$

Thus, this study has focused on abdominal trauma in tertiary care centre to identify the risk factors that have detrimental effect in prognosis. Trauma scores system besides predicting the outcome can act as benchmark upon which improvement of trauma care system is possible.

\section{METHODS}

This is prospective observational study done in three tertiary care hospitals in Kathmandu and data were collected for period of one year (June 2011 to December 2012) after ethical approval and informed consent were obtained. All patients of age more than 15 years who underwent surgical intervention for abdominal trauma were included in the study. Data obtained were patient demography; pattern, MJSBH Vol 15 Issue 2 July-Dec 2016 mode and mechanism of injury. Operative findings, operative procedure, and postoperative events and complications (clinical, lab and radiological parameters) till discharge were noted. Operative delay was defined as the time interval between incident and operative procedure. The clinical and operative findings (like age, sex, state of shock, mechanism of injury etc) were compared and correlated with postoperative outcome. Abdominal trauma index (ATI) and Injury Severity Scale (ISS) were calculated. ATI and ISS value less or equal to 15 and more than 15 were compared and correlated with postoperative outcome and complications. Data were entered in SPSS 16.0 and analyzed. The results obtained were expressed in mean \pm standard deviation (SD). Chi square test was used to investigate statistical significance and $p$ value less than 0.05 is considered significant.

The decision for operative or non operative management was made depending upon the outcome of the clinical examination and results of diagnostic tests by the registrar / consultant on duty.

\section{RESULTS}

There were total of 93 patients admitted for abdominal trauma. Out of them, 49 patients who sustained blunt trauma, underwent surgical intervention and the entire patiens (26) with penetrating abdominal trauma underwent operative intervention. Total of 75 patients who underwent surgical intervention for abdominal trauma were included. The males sustained four times more abdominal trauma than females. The details of the patient's characteristics are listed in table 1. Fall injury $(40 \%)$ and road traffic accident (14\%) and stab injury $(14 \%)$ were the three frequent causes of abdominal injury. Gastrointestinal injury was 
Table 1. Patients' characteristics

\begin{tabular}{|l|l|}
\hline Total patient & \multicolumn{1}{|c|}{75} \\
\hline Mean age in years & $31.7 \pm 14.5(15-71)$ \\
\hline Male :Female & $4.6: 1$ \\
\hline Intention of injury & $\begin{array}{l}\text { Accident (73\%), } \\
\text { assault (23\%), } \\
\text { Suicidal (2\%) }\end{array}$ \\
\hline Blunt trauma & $65.4 \%(49)$ \\
\hline Penetrating trauma & $34.6 \%(26)$ \\
\hline Associated injury & $28 \%(21)$ \\
\hline Shock at presentation & $25.3 \%(19)$ \\
\hline $\begin{array}{l}\text { Operative delay } \\
\text { (hours) }\end{array}$ & $\begin{array}{l}38.15 \pm 45.58(2- \\
168)\end{array}$ \\
\hline
\end{tabular}

detected in $38,50.6 \%$ of patient whereas spleen $12,(16 \%)$ was the commonly injured solid organ.

The overall morbidity and mortality rate were $30.6 \%$ (23) and 9.3\% (7) respectively. The septic complications observed were chest infection (18.6\%), surgical site infection $(6.6 \%)$ and abdominal septic complications $(6.6 \%)$. Increasing age, shock at presentation, operative delay $>24$ hours, multiple organ injuries are some of the predictors of the surgical outcome following abdominal trauma (Table 2). Majority (64.8\%) of the patient had delay in operation more than 12 hours. Postoperative septic complications were observed in $18.7 \%$ (9) with operative delay

Table 2. Comparisons of Predictors of surgical outcome. Figures in parenthesis denote frequency.

\begin{tabular}{|c|c|c|c|c|c|}
\hline Parameters & $\begin{array}{c}\mathrm{N} \\
\text { Total }=75\end{array}$ & $\begin{array}{c}\text { Complications rate } \\
\qquad \mathrm{N}=23(30.6 \%)\end{array}$ & $\begin{array}{c}P \\
\text { value }\end{array}$ & $\begin{array}{c}\text { Mortality rate } \\
\mathrm{N}=7(9.3 \%)\end{array}$ & $\begin{array}{c}P \\
\text { value }\end{array}$ \\
\hline \multirow[t]{2}{*}{ Age } & $<30$ years $(39)$ & $20.5 \%(8)$ & \multirow{2}{*}{$<0.05$} & $5.1 \%(2)$ & \multirow[t]{2}{*}{$<0.05$} \\
\hline & $>30$ years $(36)$ & $41.6 \%(15)$ & & $26.6 \%(5)$ & \\
\hline \multirow[t]{2}{*}{ Shock } & Present (19) & $68.4 \%(13)$ & \multirow[t]{2}{*}{$<0.05$} & $31.5 \%(6)$ & \multirow[t]{2}{*}{$<0.05$} \\
\hline & Absent (56) & $17.8 \%(10)$ & & $1.7 \%(1)$ & \\
\hline \multirow{2}{*}{$\begin{array}{l}\text { Mechanism of } \\
\text { Injury }\end{array}$} & Blunt (49) & $28.5 \%(14)$ & \multirow[t]{2}{*}{ NS } & $4 \%(2)$ & \multirow[t]{2}{*}{$<0.05$} \\
\hline & Penetrating (26) & $34.6 \%(9)$ & & $19.2 \%(5)$ & \\
\hline \multirow[t]{2}{*}{ Delay } & $<24$ hours $(48)$ & $18.7 \%(9)$ & \multirow[t]{2}{*}{$<0.05$} & $4.1 \%(2)$ & \multirow[t]{2}{*}{$<0.05$} \\
\hline & $>24$ hours $(27)$ & $52 \%(14)$ & & $18.5 \%(5)$ & \\
\hline \multirow{2}{*}{$\begin{array}{l}\text { Associated } \\
\text { injuries }\end{array}$} & Multiple (21) & $33 \%(7)$ & \multirow[t]{2}{*}{ NS } & $19.0 \%(4)$ & \multirow[t]{2}{*}{ NS } \\
\hline & Single organ (54) & $29.6 \%(16)$ & & $5.5 \%$ & \\
\hline \multirow[t]{2}{*}{ ATI } & $1-15(43)$ & $20.9 \%(9)$ & \multirow[t]{2}{*}{0.07} & $2.3 \%(1)$ & \multirow[t]{2}{*}{$<0.05$} \\
\hline & $>15(32)$ & $43.7 \%(14)$ & & $18.7 \%(6)$ & \\
\hline \multirow[t]{2}{*}{ ISS } & $1-15(69)$ & $26.0 \%(18)$ & \multirow[t]{2}{*}{0.05} & $5.8 \%(4)$ & \multirow[t]{2}{*}{$<0.05$} \\
\hline & $>15(6)$ & $83.3 \%(5)$ & & $50 \%(3)$ & \\
\hline
\end{tabular}


less than 24 hours and $52.0 \%$ (14) of patient with operative delay more than 24 hours. (p $<0.007)$.

The mean \pm standard deviation Abdominal Trauma Index (ATI) was $14.78 \pm 7.4$. (14.61 \pm 7.75 in penetrating and $14.87 \pm 7.33$ in Blunt Trauma). The mean \pm standard deviation Injury Severity Scale (ISS) was $8.9 \pm 5.7$ ranges from 1 to 36 . (12.3 \pm 7.06 in penetrating trauma and $7.05 \pm 3.85$ in blunt abdominal trauma. $92 \%$ of the patients had ISS 15 or below. Most of the patients in both blunt (57.6\%) and penetrating (55.6\%) abdominal trauma had Abdominal Trauma Index 15 or less. The ATI and ISS value more than 15 were associated with significant morbidity and mortality (table 2).

\section{DISCUSSION}

Data on abdominal trauma differ from one center to another because of geographic and economic patterns of a country, education, poverty, political and religious practice. The overall incidence of traumatic injuries was twice as common in males as in females with the ratio of $2: 1$ to $6: 1$ which reflects the greater mobility of males for work, recreation or other activities. $^{2}$
In our study seventy three percent of the abdominal trauma was due to accident and fall injury was most common cause of injury. The majority of abdominal injury happened secondary to fall $(47.5 \%)$, followed by RTA $(19.6 \%)$ and assault $(15.1 \%){ }^{3}$ Similar ratios were observed in study by Deodhar et al while road traffic accidents were common cause of abdominal injury in western countries. ${ }^{2,7}$ The high incidence of fall injury in this study is partly attributable to the hilly and mountainous geography of the country where collecting fodder from the forest is common mode of living for many.

Postoperative infectious complication is significant in age more than 30 years $(20.5 \%$ below 30 years and $41.6 \%$ above 30 years age, $\mathrm{p}$ value $<0.05$ ) that comes similar to study done in Kenya. ${ }^{8}$ Female has higher mortality (11\%) than male $(7 \%), p$ value $>0.05$. MultiInstitutional Trials Committee of the Eastern Association for the Surgery of Trauma (EAST), has concluded that the patients of both sex with age $>$ or $=55$ years has a greater mortality for all forms of treatment of their abdominal injury and failed non operative management more

Table 3. Comparison of predictors of abdominal trauma surgery outcome from various studies

\begin{tabular}{|c|c|c|c|c|c|c|c|}
\hline Predictors of Outcome & $\begin{array}{l}\text { Malinoski } \\
\text { et al }{ }^{14}\end{array}$ & $\begin{array}{l}\text { Croc } \\
\text { e et } \\
\text { al } 23\end{array}$ & $\begin{array}{l}\text { Harbrecht } \\
\text { et al }{ }^{9}\end{array}$ & $\begin{array}{l}\text { Sikhondze } \\
\text { et al }{ }^{10}\end{array}$ & $\begin{array}{l}\text { Aldemir } \\
\text { et } \mathbf{a l}^{27}\end{array}$ & $\begin{array}{l}\text { Musau } \\
\text { et } \mathbf{a l}^{8}\end{array}$ & $\begin{array}{l}\text { Our } \\
\text { study }\end{array}$ \\
\hline Age & 0.005 & - & 0.05 & - & - & 0.05 & 0.01 \\
\hline Shock & 0.01 & - & - & 0.03 & 0.00 & - & 0.04 \\
\hline Associated injury & 0.043 & - & - & 0.006 & 0.006 & - & 0.7 \\
\hline $\mathrm{ATI}>15$ & - & 0.01 & - & - & 0.00 & - & 0.4 \\
\hline ISS $>15$ & 0.04 & 0.001 & - & - & - & - & 0.003 \\
\hline Operative delay & 0.01 & & 0.008 & 0.08 & 0.009 & - & 0.002 \\
\hline
\end{tabular}


Table 4. Comparisons of Morbidity and Mortality in abdominal trauma series.

\begin{tabular}{|c|c|c|c|}
\hline Study Series & Total Cases (n) & Morbidity & Mortality \\
\hline Deodhar et al ${ }^{6}, 1983$ & 51 & $25.5 \%$ & $19.6 \%$ \\
\hline Masau et al ${ }^{8}, 2006$ & 80 & $12.5 \%$ & $12.5 \%$ \\
\hline Stewart et al ${ }^{3}, 1994$ & 110 & $16 \%$ & $8.2 \%$ \\
\hline Croce et al ${ }^{23}, 1992$ & 962 & $7.5 \%$ & $7 \%$ \\
\hline Our Study & 75 & $30.6 \%$ & $9.3 \%$ \\
\hline
\end{tabular}

frequently than patients $<55$ years ( $p$ value $<0.05){ }^{9}$

In our study infectious complication were more common in male population than female $(35 \%$ vs $11 \%$, $\mathrm{p}$ value $>0.05$. Mortality was twice more with age more than 30 years. 19 patients present in state of shock. The mortality and morbidity was significantly high in those patients ( $p$ value $<0.05$ ). Also patients with multiple organs injury and associated injuries have higher chance of complication (33\%) than single organ injury and without associated injuries (29\%). Age, ISS, Blood loss and the physiological parameters of Systolic blood pressure, pulse rate, Base deficit, Core temperature, referral delay, delay in surgery, intensive care unit admittance, GCS eye opening response and the GCS motor response were found to be independent predictors of mortality and morbidity in different trauma series study. $4,8,10-13$

$52 \%$ (27) percent of the patient had operative delay (time of incident to surgery) more than 24 hours. The delay in surgery is all due to referral from distant medical centre, transportation difficulties, delay in emergency department, low socioeconomic status and others. The postoperative septic complication with operative delay $<12$ hours, 12-24 hours and $>24$ hours were $7 \%, 14 \%$ and $52 \%$ respectively ( $\mathrm{p}$ value $<0.05)$. Delay in MJSBH Vol 15 Issue 2 July-Dec 2016 therapeutic intervention of greater than 4 hour from hospital admission can led to statistically significant increase in the septic complication rate $(\mathrm{p}<0.01)$ despite a lower injury severity scale. 3, 14 A comparable results are demonstrated by series of studies with increase in the incidence of mortality with increase in time to operative intervention (within 8 hours: 2\%; 8-16 hours: 9.1\%; 16-24 hours: $16.7 \%$; greater than 24 hours: $30.8 \%, p=0.009$ ) as did the incidence of complications. ${ }^{15,16}$

These various clinical scoring systems in abdominal trauma is useful to assess the severity of injury, predict the complications and outcome that signifies the need for specialized trauma center for the optimum management of the trauma patients. Since its introduction in 1974, the Injury Severity Score (ISS) has been considered the "gold standard" for anatomic injury severity assessment. ${ }^{17}$ The mean \pm standard deviation Abdominal Trauma Index was $14.78 \pm 7.4$. The mean \pm standard deviation Injury Severity Scale was 8.9 \pm 5.7 . $57.3 \%$ of patients sustained minor injury (ISS 15 or less), $41.3 \%$ sustain moderate injury (ISS 16-24) and $2.6 \%$ sustain severe injury (ISS $>25$ ). The mean ISS in our study is lower than the studies done in western countries (mean \pm $\mathrm{SD}$ is $38.1 \pm 19.6$ ) that may be due to high velocity and severe injuries to industrialized 
economy. ${ }^{18} 92 \%$ of the patients had ISS 15 or below.

Chest infection is the common complication and abdominal sepsis is common cause of mortality. ${ }^{8}, 19,20$ The overall mortality ranges from $7 \%$ to $20 \%$ (table 3 ). The mortality is higher in penetrating trauma than blunt trauma and has $p$ value $<0.05$. This higher percentage of morbidity and mortality seen in penetrating trauma may be attributable to higher number of organ injured and higher Injury severity scale ${ }^{3}$.

The risk of intra-abdominal sepsis increases with increasing ATI. ${ }^{5,21}$ ATI $>25$ associated with a $50 \%$ complication rate and contrasted to a $5 \%$ incidence when the ATI was equal to or less than $25 .^{22}$ In abdominal trauma patients, an ATI value greater than 15 and an ATI value greater than 25 were associated with abdominal septic complications ( $p$ less than 0.01 and $p$ less than 0.001, respectively). Complications rate and mortality rate is also attributable to multiple factors such as delay in presentation, delay in surgery, lack of trauma scoring system guided management, absence of dedicated trauma care centre or trauma surgeons. ${ }^{23}$

Increase in Injury severity scale (ISS) 15 or more is associated with increase in infectious complications. Croce et al observed ISS greater than or equal to 16 is associated with abdominal septic complications $(p<0.001)$. Thus series of studies proved that injury severity scale serve as useful tools to predict the occurrence of postoperative infectious complications in patients with abdominal trauma. ISS more than 15 was also associated with increase in mortality rate in different series of study. ${ }^{21}, 23,24$ Trauma scores in emergency medicine quantitatively characterize the severity of trauma victims' injuries and physiologic derangements. They MJSBH Vol 15 Issue 2 July-Dec 2016 are used to detect and assess patients and have applications in guiding patient care and early therapeutic decisions. In the pre-clinical setting, an effective trauma index meets the following criteria: It is highly reliable with regard to identifying high- and low-risk patients. It has high face-validity. It has high inter- and intra-rater reliability. It is easy to use and allows rapid, accurate measurements. The most widely accepted injury severity index is probably the Injury Severity Score (ISS). ${ }^{17,}$ 25, 26

\section{CONCLUSION}

Age of patients, shock at presentation, operative delay, ATI and ISS are significant predictors of surgical outcome. Morbidity are higher in our series however mortality is comparable. These predictors are guide to costeffective quality management of the patients.

\section{REFERENCES}

1. Bajracharya AA, BR Yam, CS Agrawal, Owen Lewis. Spectrum of surgical trauma and associated head injuries at a university hospital in eastern Nepal. Journal of neurosciences in rural practices 2010;1:2-8 D O I : h t t p s : / / d o i . o r g / 10.4103/0976-3147.63092

2. Joshi SK SS. A Study of Injuries and Violence Related Articles in Nepal J Nepal Med Assoc. 20065. 9;48(175):209-16

3. Stewart BT, Lee V, Danne PD. Laparotomy for trauma in a regional centre: the effect of delay on outcome. Aust N Z J Surg. 1994 Ju1;64(7):484-7. DOI: https://doi.org/ 10.1111/j.1445-2197.1994.tb02261.x

4. Alamshah SM, Pipelzadeh M, Mousavi SR, Baharanfar H, Rezapour E. Determination of predictors and risk factors in patients with multiple emergency surgical traumas. Ulus Travma Acil Cerrahi Derg. 2010 Sep;16(5): 421-6.

5. Borlase BC, Moore EE, Moore FA. The abdominal trauma index--a critical 
reassessment and validation. J Trauma. 1990 Nov;30(11):1340-4. DOI: https://doi.org/ 10.1097/00005373-199011000-00006

6. Deodhar SD, Patel NP, Shah KB, Jammihal HJ. Blunt and penetrating abdominal injuries (a study of 51 cases). J Postgrad Med. 1983 Apr;29(2):96-9.

7. Smith J, Caldwell E, D'Amours S, Jalaludin B, Sugrue M. Abdominal trauma: a disease in evolution. ANZ J Surg. 2005 Sep;75(9): 790-4. DOI:https://doi.org/10.1111/j. 1445-2197.2005.03524.x

8. Musau P, Jani PG, Owillah FA. Pattern and outcome of abdominal injuries at Kenyatta National Hospital, Nairobi. East Afr Med J. 2006 Jan;83(1):37-43. DOI: https://doi.org/ 10.4314/eamj.v83i1.9359

9. Harbrecht BG, Peitzman AB, Rivera L, Heil B, Croce M, Morris JA, Jr., et al. Contribution of age and gender to outcome of blunt splenic injury in adults: multicenter study of the eastern association for the surgery of trauma. J Trauma. 2001 Nov; 51(5):887-95 DOI: https://doi.org/ 10.1097/00005373-200111000-00010

10. Sikhondze WL, Madiba TE, Naidoo NM, Muckart DJ. Predictors of outcome in patients requiring surgery for liver trauma. Injury. 2007 Jan;38(1):65-70. DOI: https:// doi.org/10.1016/j.injury.2006.08.064

11. Gabbe BJ, Cameron PA, Wolfe R, Simpson P, Smith KL, McNeil JJ. Predictors of mortality, length of stay and discharge destination in blunt trauma. ANZ J Surg. 2005 Aug;75(8):650-6. DOI: https://doi.org/ 10.1111/j.1445-2197.2005.03484.x

12. Krishna G, Sleigh JW, Rahman H. Physiological predictors of death in exsanguinating trauma patients undergoing conventional trauma surgery. Aust N Z J Surg. 1998 Dec;68(12):826-9. DOI: https:// doi.org/10.1111/j.1445-2197.1998.tb04696.x

13. Gupta S, Talwar S, Sharma RK, Gupta P, Goyal A, Prasad P. Blunt trauma abdomen: a study of 63 cases. Indian J Med Sci. 1996 Aug;50(8):272-6.

14. Malinoski DJ, Patel MS, Yakar DO, Green D, Qureshi F, Inaba K, et al. A diagnostic delay of 5 hours increases the risk of death after blunt hollow viscus injury. J Trauma. 2010 Jul;69(1):84-7. DOI: https://doi.org/ 10.1097/TA.0b013e3181db37f5

15. Fakhry SM, Brownstein M, Watts DD, Baker CC, Oller D. Relatively short diagnostic delays $(<8$ hours) produce morbidity and mortality in blunt small bowel injury: an analysis of time to operative intervention in 198 patients from a multicenter experience. J Trauma. 2000 Mar; 48(3):408-14; discussion 14-5. DOI: https://

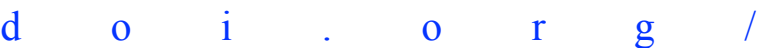
10.1097/00005373-200003000-00007

16. lamsal S. Effect on outcome of delay in surgical management of hallow viscus perforation peritonitis: an experience at Dhulikehl Hospital, Kathmandu UniversityE. JSSN. 2011;14(1):8-11.

17. Mikhail JN, Harris YD, Sorensen VJ. Injury severity scoring: influence of trauma surgeon involvement on accuracy. J Trauma Nurs. 2003 Apr-Jun;10(2):43-7. DOI: https:// d 0 i . o r r g / 10.1097/00043860-200310020-00002

18. Gennari TD, Koizumi MS. [Determination of the trauma severity level]. Rev Saude Publica. 1995 Oct;29(5):333-41. DOI: h t t p s : // d o i.org/10.1590/ S0034-89101995000500001

19. DiVincenti FC, Rives JD, Laborde EJ, Fleming ID, Cohn I, Jr. Blunt abdominal trauma. J Trauma. 1968 Nov;8(6):1004-13. D O I : h t t p s : / / d o i.o r g / 10.1097/00005373-196811000-00002

20. Stein A, Liscoss I. Selective management of penetrating wounds of abdomen. JTrauina. 1968;8:1014-25. DOI: https:// d $\begin{array}{llllllll} & \text { i } & \text { o } & \text { r } & \text { g } & \text { / }\end{array}$ 10.1097/00005373-196811000-00003

21. Agrawal V, Sharma D, Raina VK. Correlation of trauma scoring systems with abdominal septic complications in abdominal trauma. Indian J Gastroenterol. 2002 Sep-Oct;21(5):188-92.

22. Moore EE, Dunn EL, Moore JB, Thompson JS. Penetrating abdominal trauma index. J Trauma. 1981 Jun;21(6):439-45. 
23. Croce MA, Fabian TC, Stewart RM, Pritchard FE, Minard G, Kudsk KA. Correlation of abdominal trauma index and injury severity score with abdominal septic complications in penetrating and blunt trauma. J Trauma. 1992 Mar;32(3):380-7; discussion 7-8. DOI: https://doi.org/ 10.1097/00005373-199203000-00017

24. Ince H, Ince N, Taviloglu K, Guloglu R. [A different approach to trauma scoring]. Ulus Travma Acil Cerrahi Derg. 2006 Jul;12(3): 195-200.

25. Himmelseher S, Pfenninger E, Strohmenger H. [Do we need trauma scoring in emergency medicine?]. Anaesthesist. 1994 Jun;43(6):376-84. DOI: https://doi.org/ $10.1007 / \mathrm{s} 001010050070$

26. Read-Allsopp C. Establishing inter-rater reliability scoring in a state trauma system. $\mathrm{J}$ Trauma Nurs. 2004 Jan-Mar;11(1):35-9. D O I : h t t p s : / / d o i . o r g / 10.1097/00043860-200411010-00006

27. Aldemir M, Tacyildiz I, Girgin S. Predicting factors for mortality in the penetrating abdominal trauma. Acta Chir Belg. 2004 Aug;104(4):429-34. 